\title{
A Review on Seismic Performance of L-Shaped Building Through Plan Irregularities
}

\author{
Yash Chhatani ${ }^{1 *}$, Dr. Prashant Y Pawade ${ }^{2}$, Dr. Kuldeep R Dabhekar ${ }^{3}$, Dr. Isha P Khedikar ${ }^{4}$ \\ PG Student, Structural Engineering, G H Raisoni College of Engineering, Nagpur, India ${ }^{1}$ \\ Professor, Department of Civil Engineering, G H Raisoni College of Engineering, Nagpur, India ${ }^{2}$ \\ Assistant Professor, Department of Civil Engineering, G H Raisoni College of Engineering, Nagpur, India ${ }^{3,4}$ \\ "Corresponding Author: yash.chhatani72@gmail.com
}

Article Info

Volume 8 Issue 2

Page Number: 251-257

Publication Issue :

March-April-2021

\section{Article History}

Accepted : 05 April 2021

Published : 11 April 2021

\section{ABSTRACT}

The patterns of sporadic structure development have quickly expanded because of tasteful and restricted accessibility of land. Past examinations have indicated that the structures with design abnormality are harmed under solid ground movement. Auxiliary inconsistencies are significant elements which decline the seismic exhibition of the structures. Structures having basic anomalies bring about the lopsided circulation of the story float, exorbitant twist, etc. The irregularity discussed here are about plan irregularity which is available in reparticipant corners and torsional anomaly which is caused by abrupt changes in firmness and twist enhancement factor in building. This study is to propose a feasible solution to build this kind of structure in seismically active areas using analytical methods with the assistance of ETABS software. The analysis shall be done through a comparable static horizontal power technique and reaction range examination (dynamic investigation). The basic reactions will estimated regarding story displacement, inter-story drift ratio, torsional irregularity ratio, torsional diaphragm rotation, normalized base shear force, and overturning moment, which are also called seismic response demands. The structure will be analyzed and compare with different types of other shape plan.

Keywords : Seismic response demands, Plan irregularities, asymmetric building, analysis methods, ETABS.

\section{INTRODUCTION}

Seismic tremors are one of the most unusual and wrecking of cataclysmic events. Despite the fact that, the event of tremors can't be anticipated and forestalled however the structures ought to be intended to oppose quake powers [1-2]. The structure ought to have primary credits to perform well in seismic tremor, for example, straightforward and ordinary setup, sufficient sidelong quality, solidness and flexibility. To limits the earthquake- instigated hazard, it was fundamental to distinguish the seismic presentation of the manufactured climate [3]. It was accomplished through the improvement of various explanatory procedures which guarantees the construction to withstand during serious seismic 
tremors and produce enough alert at whatever point exposed to a significant quake [5]. The conduct of a structure during a quake relies upon a few variables; firmness, sufficient parallel quality, pliability, straightforward and standard designs. Among all the elements, the setup of a structure is a significant element that impacts the harm during the seismic tremor shaking. By and by, a completely ordinary structure once in a while happens. Structural anomalies may change drastically in their tendency and guideline, are hard to characterize [6-8]. Thus, the choice of the structure plan setup assumes a significant part in the basic plan for opposing seismic tremor ground shaking. The examinations on seismic activity on structures affirmed that sporadic structures go through more harm than customary structures. Along these lines, inconsistencies must be considered and limitations ought to be done on an unpredictable structure to maintain a strategic distance from a sudden change in mass and firmness. Indian standard code enrolls the abnormality in structures [9-10]. The inconsistencies are categorized as vertical and plan abnormalities. Vertical inconsistencies alluding to the abrupt difference in quality, firmness, math, and mass outcomes in the unpredictable distribution of powers or circulation over the tallness of the structure. Plan abnormalities suggest to uneven arrange-ment shapes (L-T-U-F-W) or discontinuities within the level opposing parts (stomachs, for instance, patterns, huge openings, reparticipant corners and different unforeseen changes achieving twist, abdomen distortions, and stress focus.

\section{OBJECTIVES}

The various objectives of the project are:

i. To design L-shaped building in ETABS.

ii. To study the seismic response demands of Lshaped building.

iii. To compare the L-shaped building plan with other shaped building plans.

\section{LITERATURE REVIEW}

The study [1] assesses the impact of plan design inconsistency when exposed to the differing point of the info reaction range. For this, one standard and six distinctive L-molded RC building outlines were demonstrated for mathematical examination. The investigation was done through an identical static parallel power technique and reaction range examination (dynamic investigation). [4] The auxiliary reactions were estimated as far as story dislodging, between story float proportion, torsional inconsistency proportion, torsional stomach pivot, standardized base shear power, and upsetting second. This study is of Nepal but the used Indian standard code for designing the building.
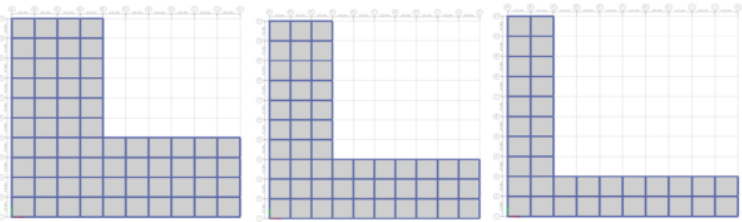

Fig 1. Different types of L-shaped building plan

In this case [2] the designed building is of Bangladesh which is one of the most tremor inclined territories in South-Asia and Sylhet is the most seismic vulnerable area in Bangladesh. Seismic execution investigation is enthusiastically prescribed to guarantee free from any danger building structures for this district. To improve performance from fortified cement (RCC) structure, new unstable plan arrangements need basic architects to perform each static and dynamic examination for the plan of structures. And they used to complete the static and dynamic investigation of building utilizing Bangladesh National Building Code (BNBC)- 2006. They studied W-shape, L-shape, Rectangular shape and Square shape 10 celebrated RCC buildings are examined utilizing ETABS and SAP2000. They found that W-shape has been discovered generally helpless for earthquake load case compared to other shape. 


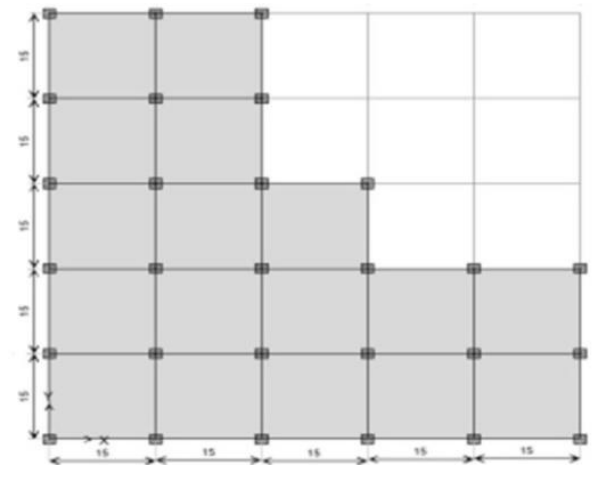

Fig 2: W-shaped building plan

In this [5-6] they study, One such type of anomaly is the presence of re-participant corners that causes pressure fixation because of unexpected changes in solidness and twist enhancement in the structures; subsequently causes early breakdown [5]. They measure the responses include inter-story drift; story shear force; overturning moment; torsion moment at the base and along the building height; top floor displacement; and torsional Irregularity Ratio. Also they formulate the six L-shape building with progressive decrease in the arrangement of reference model. The models are broke down with ETABS utilizing Equivalent Static Load and Response Spectrum Methods [6]. The outcomes demonstrate that structures with serious inconsistency are more powerless than those with customary arrangement coming about because of twist conduct, and the extra shear power delivered the opposite way to the seismic tremor input.

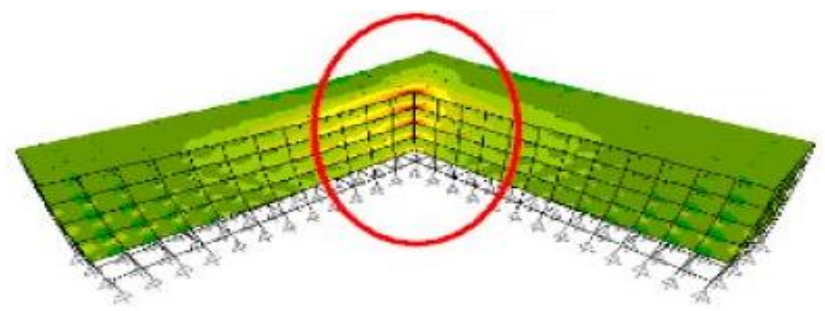

Fig 3: Stress concentration at re-entrant corner in Lshaped buildings
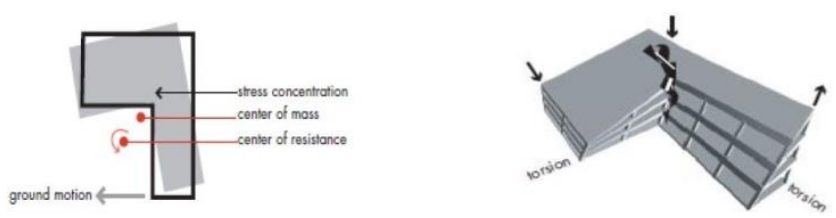

Fig 4: Damage at re-entrant corner in L-shaped buildings

In [7-8] the point of the examination announced in this paper is to get a handle on the seismic exhibition of L-formed sporadic structures with second opposing casings through an assessment of the inconsistency consequences for estimated seismic response demands [7]. They said that the results for inter-storey drift, storey shear force, overturning moment, torsionmoment responses at the base and along the building height, top-floor displacement and torsional irregularity coefficient demonstrate that structures with abnormality are more powerless than those with an ordinary arrangement coming about because of stress fixation and coupled parallel torsional conduct [8].

In many studies [9-11] they deal with the vertical irregularities of the building they proposes three conditions of constructions i.e. I-shape, and stepped buildings all are mid-rise (6 storeyed) and high rise (12 storeyed) [9]. The structures are demonstrated and investigated in programming ETABS and different seismic responses such as shear force, storey drift, storey displacement, etc. were gotten. The seismic investigation was done by IS 1893 (PART-1):2002 and seismic zone $\mathrm{V}$ has been taken for all the cases [10]. From their result point of view it was seen that in structure with mathematical inconsistency the solidness is definitely quite that of normal structure and conjointly therefore the displacement of structure with geometric irregularity is a smaller amount as compared to regular structure. It has been discovered that the story drift criteria as per IS 1893 (PART1):2002 (i.e. 0.004 times of story height was 
consummated by all the models of 3 story, six story and twelve story build-ing [11].

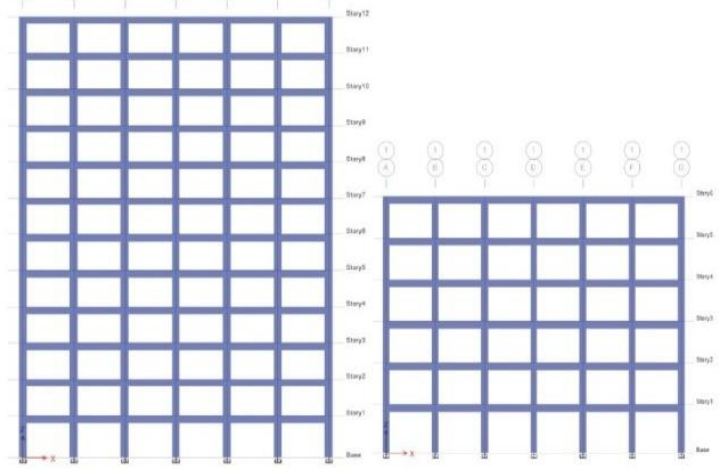

Fig 5: 12 \& 6 storeyed I-shaped frame

The advancement in research $[12,15]$ with respect to seismic reaction of plan and vertically unpredictable structure structures. Three zones of exploration are studied. The first is that the investigation of the impacts of plan-abnormality by strategies for singlestory and multi-story building models [12]. the following territory envelops detached management as a technique to alleviate torsional impacts, by strategies for base isolation and completely different styles of gadget. Ultimately, the third territory concerns vertically unpredictable structures and mishap structures [13].

In various studies [14-18] Plan arrangement irregularity present significant difficulties in the seismic plan of building. And the plan design sporadic structures have more serious harm come in the building because of over the top torsional reactions and stress fixation than normal structures [14]. Lformed structures that causes pressure focus because of abrupt changes in solidness and torsional reaction enhancement; henceforth causes early breakdown because of irregularity present in re-entrant corners [15]. They mainly focused on to explore basic seismic reaction requests for the class of L-molded structures through assessing the arrangement setup anomaly of re-entrant corners and lateral-torsion coupling effects on measured unstable response demands [16]. The measured responses embody story drift, inter-story drift, story shear force, overturning moment, torsion moment at the bottom and over building height, and torsional irregularity quantitative relation [17]. And they concluded that models with high inconsistency are more helpless because of the pressure fixation and sidelong torsional coupling conduct than that with standard structures [18].

In some papers [19-21] they perform the pushover analysis for the seismal assessment of the structure. They really perform the bifacial pushover analysis technique to beat the restrictions of current pushover strategies to assess the seismal response of irregular (both in set up and in elevation) buildings subjected to bifacial (horizontal and vertical) ground movements [19]. They designed their building as per the requirement of eurocode 8 . Ends up in phraseology of inter-story drifts and floor rotations square measure compared with those given by nonlinear response history analysis. They conclude that nonlinear static procedures are less long than nonlinear response history analysis. Be that as it may, on the grounds that most of genuine structures are sporadic, [20] pushover methods should be improved to consider the torsional impacts of structures and therefore the radial asymmetry of the seismal ground movement.

Actually the study [22] was done on experimental parameters on the seismic conduct of reinforced concrete frames with misfortunes is researched utilizing the deliberate reaction of two little scope models. And Symmetrical and unsymmetrical courses of action of setbacks are tried. The displacement, acceleration, and shear responses of the natural event frames throughout earthquake reproductions square measure compared. For calculating the result they consider the variety of delegate response maxima with base motion intensity and dispersions of high response over the peak of the frame [23]. 
The plan of structure was performed by the proposed 2005 National code of canada NBCC provisions utilizing 2 investigation ways i.e. the equivalent static force methodology and also the response spectrum analysis methodology [24]. They designed the building with mass irregularity mass irregularity and also the impact of this irregularity on building seismal response is examined for Associate in Nursing eightstory concentrically braced steel frame with numerous reverse arrangements transferral concerning surprising reductions in arrange dimensions and seismal weight on the peak of the structure.Mass abnormality is considered to exist where the seismic load of any story is over 200\% of that of its adjacent storey. And it is very important factor which affects the response of the structure under seismic loads [25].

\section{IV.CONCLUSION}

After going through all above literature reviews there were certain conclusions to be marked out for Lshaped structures some of these marked out points have been discussed below:

$\checkmark$ Various type of analysis methods are used globally.

$\checkmark \quad$ L-shape buildings are safe if they are not high rise. And it is also safe if it is only constructed in ground floor.

$\checkmark \quad$ In highly seismic prone zones the regular shape building is safer.

$\checkmark$ One of the researcher said that if we design the irregular building the semi rigid diaphragm is considered.

$\checkmark \quad$ Irregular buildings are more vulnerable because of the stress concentration in the re-entrant corner.

$\checkmark$ If we overcome the stress concentration in reentrant column and decrease the torsion effect on the building then it might be possible the irregular plan is safe.

$\checkmark \quad$ It is observed that if the stiffness and torsion amplification is more at re-entrant corner of building then there is chance of early building collapse.

$\checkmark \quad$ It is observed that for designing the irregular plan building we have to take the proper parameters with the help of IS 1893(part-1):2002.

$\checkmark \quad$ It is observed that till now Indian standard code has not had the option to incorporate the plan part of the intricate structures like L shaped buildings. From the above study, it is well known that as the abnormality increments the vulnerability of damages due to earthquakes also increases, so the designer should consider all the technical aspects to make the structure earthquake resistant.

$\checkmark \quad$ It is observed that sporadic structures are more utilized in new architectural design. In these structures the torsion phenomenon can induce detrimental stresses especially in the case of a seismic movement.

$\checkmark \quad$ From the study of all above literature review it was observed that there is still a lot of study required to make sure that the designing the Lshaped building in high seismic prone areas are really safe as per earthquake point of view. It have been observed from almost all literature review the building structures are L-shaped seems to give better results if the code provisions are sufficient and should be amended. Hence, finally from the study it can be concluded that as far as possible, the designer should take all the specialized viewpoints to make the structure seismic tremor resistant and safe. 


\section{REFERENCES}

[1]. Bharat Khanal, Hemchandra Chaulagain.: Seismic elas-tic performance of L-shaped building frames through plan Irregularities. Published by Elsevier Ltd;Structures 27 (2020) 22-36.

[2]. Mohaiminul Haque, Sourav Ray *, Amit Chakraborty, Mohammad Elias, Iftekharul Alam.: Seismic Perfor-mance Analysis of RCC Multi-Storied Buildings with Plan Irregularity. American Journal of Civil Engineer-ing (2016); 4(3): 68-73.

[3]. Momen M. M. Ahmed, Shehata E. Abdel Raheem, Mohamed M. Ahmed, Aly G. A. Abdel-Shafy.: Irregu-larity Effects On The Seismic Performance Of L-Shaped Multi-Story Buildings. Journal of Engineering Sciences Assiut University Faculty of Engineering Vol. 44 No. 5 September (2016) PP. 513 - 536.

[4]. Shehata E. Abdel Raheem, Momen M. M. Ahmed, Mohamed M. Ahmed, Aly G. A. Abdel-Shafy.:Seismic performance of L-shaped multi-storey buildings with moment-resisting frames. Proceedings of the Institu-tion of Civil Engineers (2017).

[5]. Sanyogita and Babita Saini.: Seismic Analysis of Verti-cal Irregularities in Buildings. H. Singh et al. (Eds.): ICSWMD 2018, LNCE 21, pp. 537546, 2019. Springer Nature Switzerland AG (2019).

[6]. Mario De Stefano, Barbara Pintucchi.: A review of re-search on seismic behaviour of irregular building structures since 2002. Bull Earthquake Eng (2008) 6:285-308. Springer Science+Business Media B.V. (2007).

[7]. Shehata E. Abdel Raheem, Momen M. M. Ahmed, Mohamed M. Ahmed, Aly G. A. Abdel-shafy.: Evalua-tion of plan configuration irregularity effects on seis-mic response demands of L-shaped MRF buildings. Bull Earthquake Eng (2018) 16:3845-3869. Springer
Science+Business Media B.V., part of Springer Nature (2018).

[8]. G. P. Cimellaro, A.M.ASCE.: Bidirectional Pushover Analysis of Irregular Structures. American Society of Civil Engineers (2014).

[9]. Sharon L, Wood, Associate Member, ASCE.: Seismic Response-Of R/C Frames With Irregular Profiles. Jour-nal of StructuratEngineering, Vol. 118, No. 2. American Society of Civil Engineers (1992).

[10]. Robert Tremblay and Laure Poncet.: Seismic Perfor-mance of Concentrically Braced Steel Frames in Multi-story Buildings with Mass Irregularity. Journal Of Structural Engineering, 131:1363-1375. American So-ciety of Civil Engineers (2005).

[11]. Dalal Sejal P., Vasanwala S. A., Desai A. K., "Perfor-mance based seismic design of structure: A review", International Journal of Civil And Structural Engineer-ing Volume 1, No 4,2011.

[12]. Chopra, A.K. and Goel, R.K., "A modal pushover analysis procedure to estimate seismic demands for unsymmetric-plan buildings". Earthquake Engineering and Structural Dynamics.33 (2004), pp. 903-927.

[13]. A. R. Akhare, Abhijeet A. Maske, "Performance based seismic design of R.C.C. Buildings with plan irregulari-ties" International Conference on Advances in Civil and Mechanical Engineering Systems, 19-20 Dec.2014.

[14]. Sudhanshu sood, Dr. Naveen Kwatra" Performance based seismic design of building" July 2010.

[15]. Raul Gonzalez Herrera and Consuelo Gomez So-beron,"Influence of plan irregularity of buildings", 14th World conference on Earthquake Engineer-ing,2008.

[16]. T. Mahdi and V. Soltan Gharaie, "Plan irregular RC frames:Comparison of Pushover with Nonlinear dy-namic analysis",Asian journal of 
civil engineering (building and housing) vol. 12,no. 6 (2011).

[17]. Rucha S. Banginwar, M. R. Vyawahare, P. O. Modani, "Effect of Plans Configurations on the Seismic Behav-iour of the Structure By Response Spectrum Method", International Journal of Engineering Research and Applications (IJERA) ISSN: 2248-9622,Vol. 2, Issue 3, May-Jun 2012.

[18]. Amin Alavi, Prof. P.Srinivasa Rao, "Influence of Tor-sional Irregularities of RC Buildings in High Seismic Zone", Australian Journal of Basic and Applied Sci-ences, 7(13) November 2013.

[19]. Vinod Kota Sadashiva "Quantifying structural Irregu-larity effects for simple Seismic design" university of canterbury christchurch, new zealand 2010.

[20]. Sandesh N. Suryawanshi, "Torsional Behaviour of Asymmetrical Buildings in Plan under Seismic Forc-es", International journal of emerging engineering re-search and Technology, Vol.2 (4): (2014).

[21]. M. Mouzzoun et.al, "Seismic performance assessment of reinforced concrete buildings using pushover analy-sis", IOSR Journal of Mechanical and Civil Engineer-ing, Vol.5 (1):(2013).

[22]. K. Rama Raju, M.I. Shereef, Nagesh R Iyer, S. Gopala-krishnan "Analysis And Design Of Rc Tall Building Subjected To Wind And Earthquake Loads" The Eighth Asia-Pacific Conference on Wind Engineering, December ,(2013).

[23]. Md. Rashedul Kabir, Debasish Sen, Md. Mashfiqul Is-lam "Response of multi-storey regular and irregular buildings of identical weight under static and dynamic loading in context of Bangladesh" IJCASE Volume 5, No 3, 2015.

[24]. Federal Emergency Management Agency, FEMA-440. Improvement of nonlinear static seismic analysis pro-cedures. Washington (DC); 2005.

[25]. Amitesh Dubey et.al, "Influence of diaphragm on the seismic analysis of regular and irregular frame struc-tures", International Journal of Engineering Sciences \& Research Technology, (2015).

\section{Cite this article as :}

Yash Chhatani, Dr. Prashant Y Pawade, Dr. Kuldeep R Dabhekar, Dr. Isha P Khedikar, "A Review on Seismic Performance of L-Shaped Building Through Plan Irregularities", International Journal of Scientific Research in Science, Engineering and Technology (IJSRSET), Online ISSN : 2394-4099, Print ISSN : 2395-1990, Volume 8 Issue 2, pp. 251-257, MarchApril 2021. Available at doi : https://doi.org/10.32628/IJSRSET218265 Journal URL : https://ijsrset.com/IJSRSET218265 